\title{
Wherefore Art Thou MOOC?: Defining Massive Open Online Courses
}

\author{
Stephanie J. Blackmon \\ William \& Mary \\ Claire H. Major \\ University of Alabama
}

\begin{abstract}
Although MOOCs are a much-discussed topic in higher education, conversations about MOOCs do not often include details regarding the nuanced nature of these courses. What do people mean when they use the term MOOC? In the current work, we delve into the variations of MOOCs, and we put a typology we previously created into practice. Our goal with this work is not only to provide an extended categorization for MOOCs but also to apply those categories to MOOCs that are currently advertised or already available.
\end{abstract}

Keywords: MOOC, MOOC typology, defining MOOCs

Blackmon, S. J. \& Major, C. H. (2017). Wherefore art thou MOOC?: Defining massive open online courses. Online Learning, 21(4), 195-221. doi: 10.24059/olj.v21i4.1272

\section{Wherefore Art Thou MOOC?: Defining Massive Open Online Courses}

Massive open online courses (MOOCs) are relatively new online instructional platforms for providing free instruction to anyone who can access them. The first MOOCs were offered in the late 2000s by Canadian professors teaching an online course from their campus; later, several for-profits formed for offering MOOCs, including groups such as Coursera and Udacity, as did nonprofits, such as edX. MOOCs have become fairly commonplace in higher education over the last decade. Indeed, close to 4,000 MOOCs were planned for 2016 (Wexler, 2015). Moreover, according to the MOOC Course Report, 1500 free courses were planned for May 2017, including 102 newly-developed MOOCs (Shah, 2017).

MOOCs vary widely in form, but they are said to have several defining features. As noted in Major and Blackmon (2016, p. 12-14), MOOCs are:

- Massive. Theoretically, MOOCs are massive courses, sometimes boasting participant numbers in the thousands, largely due to their often-unrestricted access (see Carver \& Harrison, 2013). However, there are also courses with much lower numbers of participants, and those courses are referred to as MOOCs as well, possibly due to the potential they hold 
for a larger number of participants. At times, smaller courses have been referred to as SMOOCs, for small to medium online courses. Despite the use of terms like SMOOC, the term MOOC seems to function as an overarching term no matter the size of the course.

- Open. The "open" aspect of MOOCs can refer to the idea that MOOCs are often free, accessible to anyone (at least in terms of enrollment), and do not require a formal admissions process. Open can also refer to MOOCs' open access roots, with some instructors allowing course materials to be refashioned, in keeping with the spirit of open access. Some MOOCs, however, are both open and closed, offering course credit for some students while allowing others to continue with the course without credit.

- Online. MOOCs are offered online. However, some instructors have students complete MOOC coursework in face-to-face settings. Despite that variation, there are still the online elements, so the purpose of the "O" for online remains quite clear.

- Courses. Although MOOCs may or may not offer credit or have a start or end date, they are still courses. They are created around specific content and typically offer a syllabus or some other layout of the material and the order of readings and events. MOOCs also typically have assignments and some form of evaluation or assessment.

Despite several common features, there are differences in how MOOCs are implemented.

Given the potential variation in form, it is not surprising that speculations about the future of MOOCs have ranged from assertions that they are a disruptive force to questions about whether they are essentially "over." Perhaps part of the disagreement over their future stems from the fact that educators and researchers really haven't developed a firm description of what a MOOC is and what it isn't. Researchers and educators need to understand the potential variations for these courses in order to fully understand their potential for higher education.

\section{Purpose}

The purpose of this article is to report the results of an examination of MOOCs through a specific lens: an instructional typology developed for classifying MOOCs (Major \& Blackmon, 2016). For this work, we examined courses advertised as MOOCs and classified them according to the essential features and elements noted on their public course materials. The goal of this work was to provide an extended categorization for MOOCs. In this way, we tested the practical utility of a MOOC typology. Clearly delineating the various forms of MOOCs, we sought to chart some of these popular courses. Our findings will be beneficial to those who teach and deliver MOOCs (and their variations) as well as to individuals who may want to take these courses.

\section{Review of Related Literature}

MOOCs are a relatively recent instructional phenomenon, and as such, the research has only just begun. At this point, it is fragmented and difficult to fully classify. However, we see three key areas of MOOC research: pedagogical, technological, and organizational.

Pedagogical. The majority of the research studies focused on MOOCs are about pedagogy, even though there is no one way to teach a MOOC, and many MOOCS do not have direct comparisons in traditional courses. There are, however, several experimental research studies dealing with the evaluation of pedagogical strategies (Anderson \& Ponti, 2014; Guo, Kim, \& 
Rubin, 2014) as well as student motivation (Milligan, Littlejohn, \& Margaryan 2013) and student engagement (Castaño, Maiz \& Garay, 2015a/b; Cheng, 2014; Sangrá, González-Sanmamed, \& Anderson, 2015; Veletsianos, 2013). In addition, some of this research focuses on e-assessment, peer-assessment, and self-assessment (Gallego, Gámiz \& Gutiérrez, 2015).

Technological. Research on the technological aspects of MOOCs often focuses on data mining and learning analytics. Newer areas of inquiry focus on technological solutions to learning issues, including human-computer interactions and technological adaptations with student progress (Vargas, 2014). Other research focuses on new tools, including video annotations that allow for interactions with multimedia and between students (Monedero, Cebrián \& Desenne, 2015).

Organizational. Dillenbourg, Fox, Kirchner, Mitchell and Wirsing (2014) suggested that integrating MOOCs in university education is one of the main challenges that MOOC providers face. It is not surprising that much of the research on organizational aspects of MOOCs focuses on how campuses use MOOCs to support learning. Some researchers investigated the use of MOOCs in learning modules on traditional campuses (e.g., Bruff, Fisher, McEwen \& Smith, 2013; Fidalgo, Sein-Echaluce, Borrás \& García Peñalvo, 2014). Other researchers have examined the use of MOOCs as reference material in flipped classrooms (e.g., Firmin, Schiorring, Whitmer, \& Willett, 2014). These studies suggest that instructors are using MOOCs in blended and flipped classrooms (Castaño et al., 2015b; Delgado Kloos et al., 2015; Israel, 2015).

Even though these three areas are emerging as a pattern of inquiry in MOOC literature, we don't know much about the different kinds of MOOCs researchers are examining. Having a system of classification would allow researchers going forward to ask more nuanced questions about pedagogical, technological, and organizational aspects and study interactions between different features and elements of MOOCs in these key areas. The current study applies the authors' typology (Major \& Blackmon, 2016) to various MOOCs. Because the application of the typology is based on publicly available content that potential MOOC participants would have prior to enrolling in a MOOC, and not on the MOOC experience, the authors did not enroll in each MOOC and did not include information on the inner workings of these courses.

\section{Conceptual Framework}

We are not the first to attempt to develop a taxonomy for MOOCs, and we sought out and examined many earlier MOOC classifications. For example, Moessinger (2013) categorized MOOCs according to who offered them: an organization (which, in this case, we mean an entity that is not a higher education institution) or an institution, including institutions that may or may not use an established MOOC platform.

Clark (2013) classified MOOCs in terms of their pedagogical functions. For example, he noted eight categories for MOOCs (Major \& Blackmon, 2016, p. 18-19):

- synchMOOCs. These MOOCs typically have a set start date, as well as set deadlines for assessments and course assignments. The courses also have fixed end dates and are usually connected to the academic calendar. The general sense is that synchronous MOOCs are constructed in a way that will aid student motivation, the development of a cohort, and maximize instructor availability.

- asynchMOOCs. Asynchronous MOOCs are often more fluid, with little to no fixed dates and times for assignments and other elements of the course. While the format may be too 
free-flowing for some, others may find that the format works better for those who need more flexibility for various reasons: e.g. residing in a different time zone than that of the institution offering the course, work obligations, etc.

- transferMOOCs. These MOOCs move existing courses to a MOOC platform. Clark noted that courses offered by Coursera qualify as transferMOOCs. These MOOCs are similar to more traditional classes and may rely on the name of an institution to draw participants.

- adaptiveMOOCs. These courses rely on algorithms for personalization of the course experience, and they use analytics to improve and adjust the course for future offerings. They also use prerequisites to provide users with unique, personalized experiences. The courses often have a linear structure.

- madeMOOCs. These courses take a more innovative approach and can be viewed as more vocational because of their emphasis on building skills in participants. The courses can often include peer-driven activities to manage the increased student-instructor ratio. Clark (2013) stated that courses from Udacity often have these characteristics.

- miniMOOCSs. With their more concentrated focus and shorter timeframe, miniMOOCs can aid students in mastering content in a matter of hours or days. These courses often have very explicit learning objectives and have been associated with Open Badges.

- connectivistMOOCS. Connectivist MOOCs, also known as cMOOCs, focus on networked learning and encouraging participants to leverage networks to expand their learning. cMOOCs also often require participants to have a product at the end of the course experience.

- groupMOOCs. These MOOCs focus on student retention and begin with a small group of students who collaborate. Groups are organized according to various categories and are dismantled and restructured during the course. Mentors are also a part of each group, and the groups can comment on each other's progress.

Siemens' (2012) approach is one of the earliest categorizations and perhaps one of the most often used to date. He described MOOCs according to pedagogy: cMOOCs and xMOOCs. cMOOCs, as noted previously, are based in a connectivist pedagogy. According to Siemens (2014), connectivism "is the integration of principles explored by chaos, network, and complexity and self-organization theories" and is "driven by the understanding that decisions are based on rapidly altering foundations" (p. 7). The principles of connectivism are as follows:

- Learning and knowledge rests in diversity of opinions

- Learning is a process of connecting specialized nodes or information sources

- Learning may reside in non-human appliances

- Capacity to know more is more critical than what is currently known

- Nurturing and maintaining connections is needed to facilitate continual learning

- Ability to see connections between fields, ideas, and concepts is a core skill

- Currency (accurate, up-to-date knowledge) is the intent of all connectivist learning activities 
- Decision-making is itself a learning process. Choosing what to learn and the meaning of incoming information is seen through the lens of a shifting reality. While there is a right answer now, it may be wrong tomorrow due to alterations in the information climate affecting the decision. (Siemens, 2014)

Downes, an early pioneer of MOOCs, coined the term xMOOCs. He suggested that xMOOCs are based on traditional pedagogy and traditional university courses.

In addition, Conole (2013) categorized MOOCs according to degrees-low, medium, and high_-for numerous areas, including

- The degree of openness,

- The scale of participation (massification),

- The amount of use of multimedia,

- The amount of communication,

- The extent to which collaboration is included,

- The type of learner pathway (from learner-centered to teacher-centered and highly structured),

- The level of quality assurance,

- The extent to which reflection is encouraged,

- The level of assessment,

- How informal or formal it is,

- Autonomy, and

- Diversity.

These ideas suggested to us that we should be looking across multiple categories and allow for variation within categories instead of making the system binary.

\section{Methods}

The research questions for our study are as follows:

1. Along what lines do MOOCs differ from each other?

2. What patterns of offerings are evident in the data?

\section{Typology}

To answer these questions, we applied a typology for classifying MOOCs (Major \& Blackmon, 2016). Typologies are organized systems of types. They are a well-established analytic tool in social science fields. They can contribute to several diverse analytic tasks such as forming and refining concepts, drawing out underlying dimensions, creating categories for classification and measurement, and sorting cases. Typologies can help researchers form concepts, refine measurement, explore dimensionality, and organize explanatory claims (Collier, LaPorte, \& Seawright, 2012). Well-known typologies include Weber's (1978) distinction among traditional, charismatic, and rational authority, and Krasner's (1977) discussion of makers, breakers, and takers in the formation of international regimes. 
Based upon our research and our conceptual framework, we developed the following typology, an extension of our previous work:

\begin{tabular}{|c|c|c|c|}
\hline Dimension & $\begin{array}{l}\text { Research } \\
\text { grounding }\end{array}$ & $\begin{array}{l}\text { Conceptual } \\
\text { grounding }\end{array}$ & Aspects \\
\hline Affiliation & Organizational & Moessinger & $\begin{array}{l}\text { Hosted by companies or universities } \\
\text { Universities run independently } \\
\text { No affiliation }\end{array}$ \\
\hline Size & Organizational & Conole & $\begin{array}{l}\text { Massive }(10,000 \text { or more) } \\
\text { Medium }(5,000-10,000) \\
\text { Small (fewer than } 5,000)\end{array}$ \\
\hline Accessibility & Organizational & Conole & $\begin{array}{l}\text { Open (open to anyone at anytime) } \\
\text { Open and closed (open to anyone at specific } \\
\text { times) } \\
\text { Closed or private (open to certain people at } \\
\text { specific times) }\end{array}$ \\
\hline Duration & Organizational & Clark & $\begin{array}{l}\text { Long term ( } 15 \text { weeks or more }) \\
\text { Medium term ( } 6-15 \text { weeks }) \\
\text { Short term (fewer than } 6 \text { weeks) }\end{array}$ \\
\hline Timing & Technological & Clark & $\begin{array}{l}\text { Synchronous } \\
\text { Asynchronous }\end{array}$ \\
\hline $\begin{array}{l}\text { Relation to } \\
\text { knowledge }\end{array}$ & Pedagogical & $\begin{array}{l}\text { Mason \& Rennie } \\
\text { Siemens } \\
\text { Clark }\end{array}$ & $\begin{array}{l}\text { cMOOCs } \\
\text { xMOOCs }\end{array}$ \\
\hline Content & Pedagogical & Mason \& Rennie & $\begin{array}{l}\text { Fixed } \\
\text { Emergent }\end{array}$ \\
\hline Structure & Technological & Clark & $\begin{array}{l}\text { Linear } \\
\text { Adaptive }\end{array}$ \\
\hline $\begin{array}{l}\text { Authority and } \\
\text { control }\end{array}$ & Pedagogical & $\begin{array}{l}\text { Dabbagh } \\
\text { Conole }\end{array}$ & $\begin{array}{l}\text { Teacher centered/driven } \\
\text { Learner centered/driven }\end{array}$ \\
\hline Pedagogy & Pedagogical & Dabbagh & $\begin{array}{l}\text { Traditional } \\
\text { Innovative }\end{array}$ \\
\hline
\end{tabular}

Table 1. A Typology for Classification of MOOCs

\section{Data Sources}

We developed a purposeful sample of courses, choosing maximum variation sampling. To locate courses, we culled lists from the major MOOC providers (MOOC List, 2017). Schreir (2014) indicated that qualitative content analysis is systematic, so we took the following steps:

Step 1: Selected MOOCs that fulfilled a number of categories (so courses hosted by companies or universities, courses run independently from universities/colleges, courses with no 
affiliation to a formal institution). We also attempted to select courses that were various sizes (e.g. massive or medium) and types (e.g. cMOOCs or xMOOCs). There are 30 MOOCs included in the current work.

Step 2: We attempted to ensure coverage across disciplines and fields, including humanities, social sciences, professional studies, and health.

Through our search, we identified the following MOOCs:

- MOOC MOOC: Critical Pedagogy (doubled MOOC intentional)

- DS 106: Digital StoryTelling (ds106)

- Masterpieces of World Literature

- Physical Theatre: Exploring the Slap

- Creative Writing: The Craft of Character

- Theatre and Globalization

- M101JS: MongoDB for Node.js Developers

- Developing Software Using Design Thinking

- A Developer's Guide to Exploring and Visualizing IoT Data

- Computation Structures 3: Computer Organization

- Accounting and Finance for IT professionals

- Agriculture, Economics and Nature

- Economic Growth and Distributive Justice Part II-Maximize Social Wellbeing

- Statistical Shape Modelling: Computing the Human Anatomy

- China's Perspective on Climate Change

- The Genomics Era: The Future of Genetics in Medicine

- Bioelectricity: A Quantitative Approach

- Climate Change Mitigation in Developing Countries

- Applying to U.S. Universities

- Teaching Mathematics with Technology

- Art \& Activity: Interactive Strategies for Engaging with Art

- To Flip or not to Flip-Discover the Flipped Classroom Methodology

- Disciplinary Literacy for Deeper Learning

- Cultural Diversity in Your Classroom

- Advanced Linear Models for Data Science 1: Linear Models

- Basic Data Descriptors, Statistical Distributions, and Application to Business Decisions

- Rethinking International Tax Law

- Business Fundamentals: Effective Networking

- Disability and a Good Life: Working with Disability

- Introduction to Business Decision Modeling with DMN

\section{Data Analysis}

We applied the full typology to each course. We worked systematically through public information about each course. For this initial analysis, we drew upon qualitative content analysis and keyword analysis of the MOOCs. According to Schreir (2014), qualitative content analysis involves "describing the meaning of qualitative data" (p. 170). In keeping with qualitative content analysis, we focused on information about the MOOCs that related to the components of our 
typology, since our research questions for this text center on the implementation of that typology. We also used keyword analysis and highlighted those terms and phrases from our typology as they appeared in the course descriptions and other information about the courses. Some information was easily accessible, such as affiliation, duration, and timing, and some was not as easily accessible. For example, finding the course size information was sometimes challenging because not all courses listed information about course size. However, if we could glean data about course size from the course description, syllabus, or other materials provided, then we noted that in our chart.

\section{Trustworthiness}

The basis of our efforts at trustworthiness include triangulation. We used multiple data sources for each MOOC from multiple MOOC providers. For example, we reviewed the general websites for each MOOC, the syllabi, and available video content. Because we relied on each course's descriptions and other course information to apply the typology, we have included a brief verbatim description of each course exactly as noted on the course website, as well as a hyperlink to expanded details regarding each course, which is a form of thick description. Therefore, the descriptions are direct quotes from the websites and include the citations as well as hyperlinks to the courses (see Appendix A).

\section{Results}

The results for the current study are organized according to the typology categories (Major \& Blackmon, 2016) and displayed on corresponding charts, where appropriate. The course names are abbreviated.

\section{Affiliation}

The chart below shows the courses and their respective affiliations. The more popular platforms are listed as categories along with a category for "Other" platforms, with the respective names of institutions and platforms alongside the corresponding courses.

\begin{tabular}{|c|c|c|}
\hline Provider & Course & Partner \\
\hline edX & $\begin{array}{l}\text { - World Literature } \\
\text { - } \quad \text { Computation Structures } 3 \\
\text { - } \quad \text { China...Climate Change }\end{array}$ & $\begin{array}{ll}\text { - } & \text { Harvard } \\
\text { - } & \text { MIT } \\
\text { - } & \text { Tsinghua University }\end{array}$ \\
\hline Coursera & $\begin{array}{ll}\text { - } & \text { Creative Writing } \\
\text { - } & \text { Theater and Globalization } \\
\text { - } & \text { Accoloper's Guide...IoT Data } \\
\text { - } & \text { Agriculture, Economic and Nature } \\
\text { - } & \text { Economic Growth...Part II } \\
\text { - } & \text { Climatectricity } \\
\text { - } & \text { Applying to U.S. Universities } \\
\text { - } & \text { Art \& Activity }\end{array}$ & $\begin{array}{ll}\text { - } & \text { Wesleyan University } \\
\text { - } & \text { Ludwig-Maximillians-Universität } \\
\text { - } & \text { IBM } \\
\text { - } & \text { Indian School of Business } \\
\text { - } & \text { University of Western Australia } \\
\text { - } & \text { Tel Aviv University } \\
\text { - } & \text { Duke } \\
\text { - } & \text { University of Cape Town } \\
\text { - } & \text { Thiversity of Pennsylvania } \\
\end{array}$ \\
\hline
\end{tabular}

Table 2. Affiliation 


\begin{tabular}{|c|c|c|}
\hline & $\begin{array}{ll}\text { - } & \text { Advanced Linear Models } 1 \\
\text { - } & \text { Basic Data Descriptors } \\
\text { - } & \text { Rethinking International Law }\end{array}$ & $\begin{array}{ll}\text { - } & \text { Johns Hopkins University } \\
\text { - } & \text { Rice University } \\
\text { - } & \text { Universiteit Leiden }\end{array}$ \\
\hline FutureLearn & $\begin{array}{l}\text { - } \text { Physical Theatre } \\
\text { - } \quad \text { Statistical Shape Modelling } \\
\text { - } \text { Genomics Era } \\
\text { - } \quad \text { Business Fundamentals } \\
\text { - } \quad \text { Disability \& a Good Life }\end{array}$ & $\begin{array}{l}\text { - University of Leeds } \\
\text { - } \quad \text { University of Basel } \\
\text { - } \quad \text { St. George's University } \\
\text { - } \quad \text { The Open University } \\
\text { - } \quad \text { UNSW Australia }\end{array}$ \\
\hline Other & $\begin{array}{ll}\text { - } & \text { MOOC MOOC } \\
\text { - } & \text { DS106 } \\
\text { - } & \text { M101JS: MongoDB } \\
\text { - } & \text { Developing Software...Design Thinking } \\
\text { - } & \text { Teaching Math w/Tech } \\
\text { - } & \text { To Flip or Not to Flip } \\
\text { - } & \text { Disciplinary Literacy...Learning } \\
\text { - } & \text { Cultural Diversity in Your Classroom } \\
\text { - } & \text { Intro to Business Decision Modeling }\end{array}$ & $\begin{array}{ll}\text { - } & \text { Digital Pedagogy Lab } \\
\text { - } & \text { University of Mary Washington } \\
\text { - } & \text { MongoDB University } \\
\text { - } & \text { PAP: Systeme, Anwendungen and } \\
\text { - } & \text { The Friday Institute for Educational } \\
\text { - } & \text { Politecnico di Milano, POK-Polimi Open } \\
\text { - } & \text { NC State University, MOOC-Ed } \\
\text { - } & \text { School Education Gateway, Directorate } \\
\text { General for Education and Culture of the } \\
\text { European Commission, SchoolEducation } \\
\text { Gateway } \\
\text { Signavio, mooc.house }\end{array}$ \\
\hline
\end{tabular}

Table 2 (cont). Affiliation

Although the major platforms like Coursera and FutureLearn partnered with several universities to provide MOOCs, there are a number of other outlets that provided MOOCs as well. For example, a university and an organization both used MOOC-Ed, and certain areas of the world offered platforms to provide MOOCs in their particular regions, such as POK for Politecnico di Milano.

There were also a number of non-U.S. universities offering MOOCs, and Coursera partnered with many of them. For example, they listed MOOCs connected with the University of Cape Town, the Indian Business School, and Tel Aviv University. There was also a non-U.S. institution for edX, Tsinghua University, and several for platforms categorized as Other. However, Coursera boasted a higher number of partnerships with non-U.S. outlets.

\section{Size}

None of the courses indicated a size; however, the MOOC MOOC: Critical Pedagogy webpage indicates that the course is focused on community building, not "amassing registrants" (Digital Pedagogy Lab, 2017). The lack of size data shows yet another distinction between MOOCs and traditional online courses. Even in traditional online classes, participants have a sense of the course size because they can access that information during the more formal registration process. For MOOCs, however, that information was uniformly omitted. 


\section{Accessibility}

The chart on accessibility is divided into four categories: open, which includes information on timeframes for accessing certain courses, as well as other forms of accessibility such as language; free, which includes courses that did not have a paid certificate option, although some had credentials available for completing certain course tasks; free to audit, which includes courses that had a paid certificate option; and paid credential option, which includes the type of certificate and cost, if available.

\begin{tabular}{|c|c|}
\hline Open & 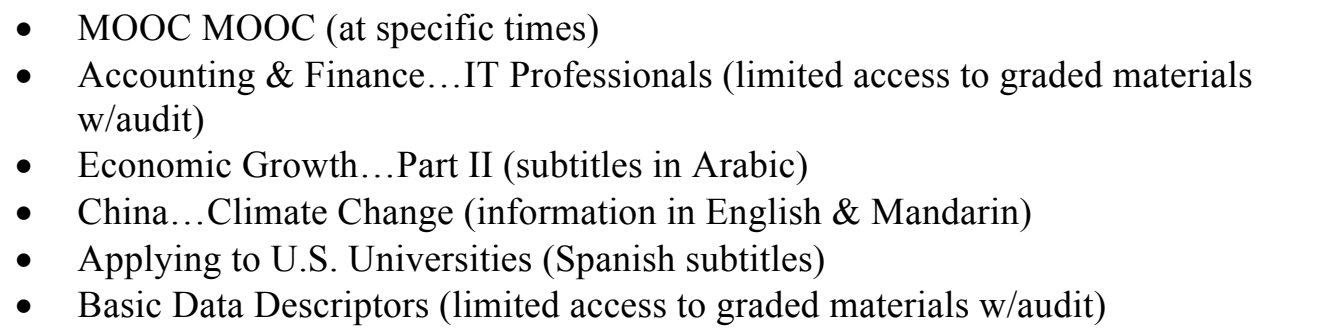 \\
\hline Free & 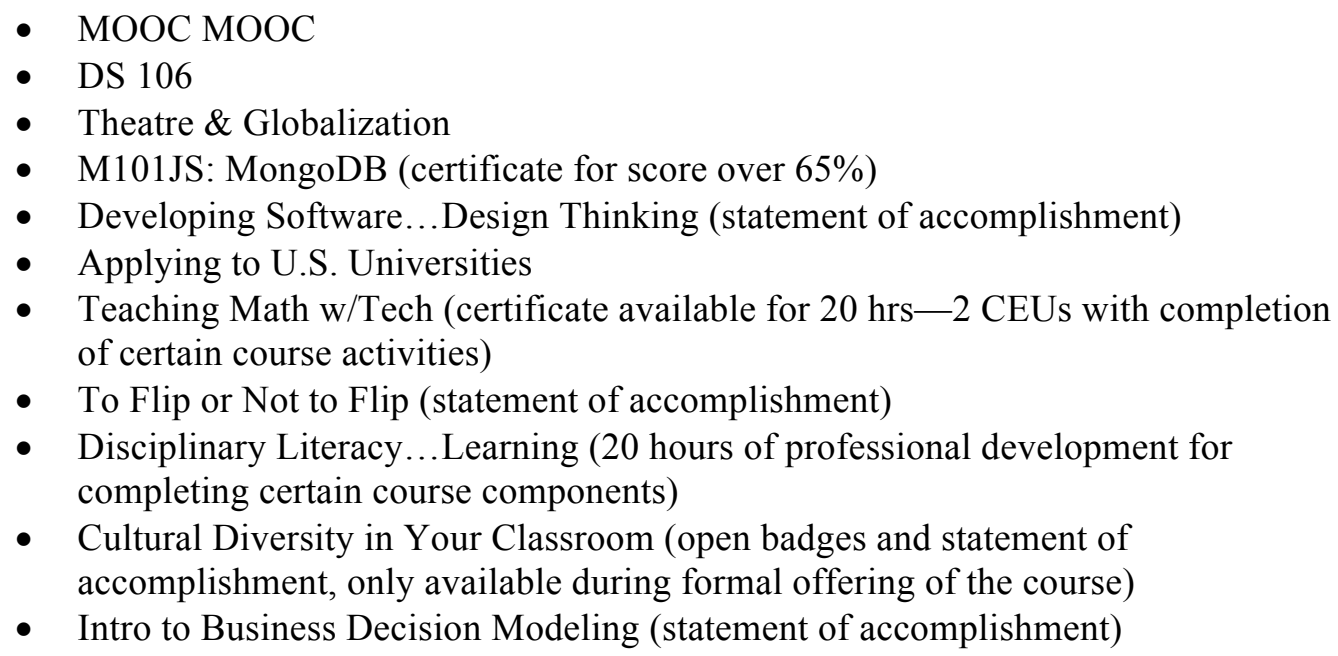 \\
\hline Free for Audit & $\begin{array}{l}\text { - } \text { World Literature } \\
\text { - } \text { Physical Theatre } \\
\text { - } \text { Creative Writing } \\
\text { - } \text { Developer's Guide...IoT Data } \\
\text { - } \text { Accounting \& Finance...IT Professionals } \\
\text { - } \text { Agriculture, Economics and Nature } \\
\text { - } \text { Economic Growth...Part II } \\
\text { - Statistical Shape Modelling } \\
\text { - China...Climate Change } \\
\text { - Genomics Era } \\
\text { - } \text { Bioelectricity } \\
\text { - Climate Change...Developing Countries } \\
\text { - Art \& Activity }\end{array}$ \\
\hline
\end{tabular}

Table 3. Structure 


\begin{tabular}{|c|c|}
\hline & $\begin{array}{ll}\text { - } & \text { Advanced Linear Models...1 } \\
\text { - } & \text { Basic Data Descriptors... } \\
\text { - } & \text { Rethinking International Law } \\
\text { - } & \text { Business Fundamentals } \\
\text { - } & \text { Disability \& a Good Life }\end{array}$ \\
\hline $\begin{array}{l}\text { Paid Credential } \\
\text { Option }\end{array}$ & $\begin{array}{ll}\text { - } & \text { World Literature ( } \$ 99 \text { certificate) } \\
\text { - } & \text { Physical Theatre }(\$ 39 \text { certificate) } \\
\text { - } & \text { Developer's Guide...IoT Data }(73 € \text { certificate) } \\
\text { - } & \text { Computation Structures } 3 \text { ( } \$ 49 \text { certificate) } \\
\text { - } & \text { Accounting \& Finance...IT Professionals (paid certificate) } \\
\text { - } & \text { Agriculture, Economics and Nature, (paid certificate) } \\
\text { - } & \text { Economic Growth...Part II ( } 43 € \text { certificate) } \\
\text { - } & \text { Statistical Shape Modeling ( } \$ 49.39 \text { certificate of achievement + transcript; } \\
\text { - } & \text { China...Climate Change }(\$ 49 \text { certificate) } \\
\text { - } & \text { Genomics Era ( } \$ 104 \text { certificate of achievement and unlimited access to course) } \\
\text { - } & \text { Bioelectricity (paid certificate) } \\
\text { - } & \text { Art \& Activity (paid certificate) } \\
\text { - } & \text { Advanced Linear Models...1 (paid certificate) } \\
\text { - } & \text { Basic Data Descriptors... (paid certificate) } \\
\text { - } & \text { Rethinking International Law (paid certificate) } \\
\text { - } & \text { Business Fundamentals ( } \$ 64 \text { certificate of achievement, unlimited access, access } \\
& \text { to tests) } \\
\text { - } & \text { Disability \& a Good Life (49 GBP certificate) }\end{array}$ \\
\hline
\end{tabular}

Table 3 (cont). Structure

Credentialing is a large part of the MOOC experience. However, there were some courses that offered a paid credentialing service but did not indicate the cost on the course page. There were also limitations associated with auditing courses that offered a paid certificate. For example, those who only audited the Basic Data Descriptors...course had limited access to graded materials with the free-to-audit option. Also, all of the courses that offered credentialing were xMOOCs, where there is no emphasis on connectivism and production like there is for cMOOCs. One could argue that the $\mathrm{xMOOC}$ experience has become tiered in some way-with those looking to access information possibly signing up for the audit-only option and those looking for a credential and opportunities to interact with others in the course opting for the paid certificate.

Although all the courses were considered open, there is the matter of the various forms of open. For example, our research indicated that the idea of course openness went beyond issues of when participants could access the course and extended to openness in terms of language. The courses Economic Growth... Part II, China...Climate Change, and Applying to U.S. Universities all provided options for course materials in languages other than English, which could lead to the courses being more open to those who are more comfortable with those languages. 


\section{Duration}

The chart for duration outlines the timeframes for each course as well as additional information pertinent to the availability of course materials.

\begin{tabular}{|c|c|}
\hline Duration & Courses \\
\hline $\begin{array}{l}5 \text { units (or sessions, } \\
20-30 \text { hours) }\end{array}$ & - Teaching Math w/Tech \\
\hline 6 units & - Disciplinary Literacy...Learning \\
\hline 2 weeks & - Physical Theatre \\
\hline 3 weeks & - Cultural Diversity in Your Classroom \\
\hline 4 weeks & $\begin{array}{l}\text { - } \text { Creative Writing } \\
\text { - } \text { Developer's Guide...IoT Data (180 days of course access) } \\
\text { - } \text { Accounting \& Finance...IT Professionals } \\
\text { - } \text { Applying to U.S. Universities } \\
\text { - Art \& Activity } \\
\text { - } \text { Basic Data Descriptors... } \\
\text { - } \text { Business Fundamentals } \\
\text { - Intro to Business Decision Modeling }\end{array}$ \\
\hline 5 weeks & $\begin{array}{l}\text { - Economic Growth...Part II (180 days of course access) } \\
\text { - Genomics Era } \\
\text { - To Flip or Not to Flip }\end{array}$ \\
\hline 6 weeks & $\begin{array}{l}\text { - } \text { MOOC MOOC (January 19, 2015-February 27, 2015) } \\
\text { - } \text { Theatre \& Globalization } \\
\text { - } \text { Climate Change...Developing Countries } \\
\text { - } \text { Advanced Linear Models...1 } \\
\text { - } \quad \text { Rethinking International Law (with } 180 \text { days of course access) } \\
\text { Disabily \& a Good Life }\end{array}$ \\
\hline 7 weeks & $\begin{array}{l}\text { - M101JS: MongoDB } \\
\text { - Developing Software...Design Thinking (6 weeks of } \\
\text { coursework and } 1 \text { for final project) } \\
\text { - Agriculture, Economics and Nature } \\
\text { - Bioelectricity ( } 180 \text { days of course access) }\end{array}$ \\
\hline 8 weeks & - Statistical Shape Modelling \\
\hline 10 weeks & $\begin{array}{l}\text { - } \quad \text { Computation Structures } 3 \\
\text { - } \quad \text { China...Climate Change (listed as self-paced) }\end{array}$ \\
\hline 12 weeks & - World Literature \\
\hline 15 weeks & - $\mathrm{DS} 106$ \\
\hline
\end{tabular}

Table 4. Duration 
The duration of the MOOCs varied, with the shortest listed as 2 weeks (Physical Theatre), and the longest listed as 15 weeks (DS106). Two of the courses, Disciplinary Literacy...Learning and Teaching Math w/Tech, only listed the number of units for the MOOC, which seemed to imply that participants could complete and access the courses at any time; these courses were not timebound, a factor not originally considered when we created the typology. That could also mean that there were no interactive opportunities in the courses because participants were almost always completing course tasks at drastically different times. DS106, at 15 weeks, and World Literature, at 12 weeks, both seemed to fit a more traditional academic calendar.

\section{Timing}

The Timing category of the typology discussed whether each course was synchronous or asynchronous. All of the courses were asynchronous, but the MOOC MOOC course had synchronous sessions available via outlets like Twitter and Google Hangout each week. Previous categorizations discussed synchMOOCs and asynchMOOCs (Clark, 2013), but MOOC MOOC employed aspects of both, making it a type of hybrid MOOC. Although the chart shows variations between the cMOOCs and xMOOCs, there were also variations between the cMOOCs as well, with MOOC MOOC offering synchronous and asynchronous components for connectivity and DS106 offering asynchronous components for connectivity.

\section{Relation to Knowledge}

The following chart shows which courses were categorized as cMOOCs and which were categorized as XMOOCs. Because xMOOCs are not often discussed in terms of their opportunities for connecting, we noted when an xMOOC description included information about creating connections in the course.

\begin{tabular}{|l|l|}
\hline cMOOC & - MOOC MOOC \\
- DS106
\end{tabular}

Table 5. Relation to Knowledge 


\begin{tabular}{|l|l|}
\hline - Climate Change...Developing Countries \\
- Applying to U.S. Universities \\
- Teaching Math w/Tech (with some focus on interactive peer components) \\
- Art \& Activity (participants encouraged to share on discussion forum) \\
- To Flip or Not to Flip \\
- Disciplinary Literacy...Learning \\
- "communal Diversity in Your Classroom (with focus on learning as a \\
- Advanced Linear Models...1 \\
- Basic Data Descriptors... \\
- Business Fundamentals \\
- Disability \& a Good Life \\
- Intro to Business Decision Modeling
\end{tabular}

Table 5 (cont). Relation to Knowledge

Only two of the courses, MOOC MOOC and DS106, were identified as cMOOCs, and the rest were xMOOCs. However, Table 5 shows that 7 of the 28 xMOOCs made it a point to highlight opportunities for community building and other forms of peer interaction in the course. Several of those interactive opportunities involved peer review. For example, Developer's Guide...IoT Data and Accounting \& Finance... IT Professionals both mentioned peer review as a component of each course. Other courses mentioned the discussion forum, group exercises, and sharing activities.

\section{Content}

The Content category includes the MOOCs that had fixed content and the ones that had emergent content. MOOC MOOC and DS106 were the only courses that had emergent content. Because of the size of many MOOCs, the idea of emerging content could seem daunting. Instructors would have to adjust content day-to-day or week-to-week, depending on the goals for courses and assignments. MOOC MOOC had fixed course information but also based course content on the contributions of MOOC participants.

\section{Structure}

The category on course structure addresses which of the courses had linear structures and which had adaptive structures. Like the previous typology category for Content, the two cMOOCs seemed to be more flexible in terms of course structure. Both MOOC MOOC and DS106 had adaptive course structures, and the other MOOCs, xMOOCs, had linear structures. Although DS106 did not show emergent course data like MOOC MOOC for the Content category, the usergenerated course content of MOOC MOOC and the emphasis on interaction via user contributions in DS106 made their course models more adaptive. The formats for the xMOOCs listed were more linear.

\section{Authority and Control}

The Authority and Control chart indicates which courses were teacher-centered, with the instructors providing most of the content for the course as evidenced by the descriptions and assignments, and learner-centered, with MOOC participants providing more of the content for the course, also as evidenced by descriptions and assignments. 


\begin{tabular}{|c|c|c|}
\hline & Learner-Centered & Teacher-Centered \\
\hline MOOC MOOC & $\mathrm{X}$ & \\
\hline DS106 & $\mathrm{X}$ & \\
\hline World Literature & & $X$ \\
\hline Physical Theatre & $\mathrm{X}$ & \\
\hline Creative Writing & & $\mathrm{X}$ \\
\hline Theatre \& Globalization & & $\mathrm{X}$ \\
\hline M101JS: MongoDB & & $\mathrm{X}$ \\
\hline $\begin{array}{l}\text { Developing Software...Design } \\
\text { Thinking }\end{array}$ & & $\mathrm{X}$ \\
\hline Developer's Guide...IoT Data & & $\mathrm{X}$ \\
\hline Computation Structures 3 & & $\mathrm{X}$ \\
\hline $\begin{array}{l}\text { Accounting \& Finance...IT } \\
\text { Professionals }\end{array}$ & & $\mathrm{X}$ \\
\hline Agriculture, Economics and Nature & & $\mathrm{X}$ \\
\hline Economic Growth...Part II & & $\mathrm{X}$ \\
\hline Statistical Shape Modelling & & $\mathrm{X}$ \\
\hline China...Climate Change & & $X$ \\
\hline Genomics Era & & $\mathrm{X}$ \\
\hline Bioelectricity & & $\mathrm{X}$ \\
\hline $\begin{array}{l}\text { Climate Change... Developing } \\
\text { Countries }\end{array}$ & & $\mathrm{X}$ \\
\hline Applying to U.S. Universities & & $\begin{array}{l}X \text { (with the exception of a self- } \\
\text { assessment portion for students, } \\
\text { which is learner focused) }\end{array}$ \\
\hline Teaching Math w/Tech & & $\mathrm{X}$ \\
\hline Art \& Activity & & $X$ \\
\hline To Flip or Not to Flip & $\begin{array}{l}\mathrm{X} \text { (reflection on the MOOC } \\
\text { itself and focus on learners' } \\
\text { courses) }\end{array}$ & $\mathrm{X}$ (providing of content) \\
\hline Disciplinary Literacy...Learning & & $\begin{array}{l}\mathrm{X} \text { (with some learner-centered } \\
\text { components based on individual } \\
\text { projects) }\end{array}$ \\
\hline
\end{tabular}

Table 6. Authority and Control 


\begin{tabular}{|c|c|c|}
\hline & Learner-Centered & Teacher-Centered \\
\hline $\begin{array}{l}\text { Cultural Diversity in Your } \\
\text { Classroom }\end{array}$ & & $\mathrm{X}$ \\
\hline Advanced Linear Models...1 & & $\mathrm{X}$ \\
\hline Basic Data Descriptors... & & $\mathrm{X}$ \\
\hline Rethinking International Law & & $\mathrm{X}$ \\
\hline Business Fundamentals & & $X$ \\
\hline Disability \& a Good Life & & $\mathrm{X}$ \\
\hline $\begin{array}{l}\text { Intro to Business Decision } \\
\text { Modeling }\end{array}$ & & $\mathrm{X}$ \\
\hline
\end{tabular}

Table 6. Authority and Control

We found that although six of the courses had learner-centered elements, only four of the courses were structured in a learner-centered format. In the current category, both of the cMOOCs and two of the xMOOCs were learner-centered. For example, in To Flip or Not to Flip, although the instructor determined the general direction of the course, one focal point of the class was participants' application of course principles to their own classes. Therefore, even though instructors provided guidance, the course, and others listed as learner-centered, centered on the contributions of learners. Although some of the other courses had learner-centered opportunities at one or more points during the class, the courses, on the whole, were not learner-centered, at least based on the information provided on their websites, syllabi, and available videos.

\section{Pedagogy}

The Pedagogy category notes the courses that follow a traditional format-where the assignments, course structure, and content followed what is usually associated with face-to-face and non-MOOC online courses - and those that followed a more innovative format. Only two of the courses, MOOC MOOC and DS106, had innovative course formats. Beyond the fact that both courses were cMOOCs, MOOC MOOC and DS106 functioned in innovative ways that were not exactly the same. For example, MOOC MOOC, as noted earlier, had both fixed and emergent content, and synchronous as well as asynchronous properties. DS106, on the other hand, relied on connectivist activities such as syndicated blog posts and participants' iterative and interactive practices.

\section{Discussion}

We recognized several patterns across typology categories. For example, most of the courses from a particular company employed a similar pedagogical approach. This is expected because the platform capabilities have a strong influence on what can and will be done pedagogically (technology is not neutral). Content is also related, as a company-based MOOC tends to use fixed readings, whereas some of the independently-offered MOOCs work from a less content-centered model, and thus content emerges as the course progresses. We also recognized that we needed to adjust our typology to address the variations related to duration, as there was a 
distinction between courses that were time-bound and courses that were not time-bound.

Another more recent development is MOOC certification. Often, those perusing the MOOC lists were offered the option to audit a course for free or pay (prices varied) for certification. Auditing a course for free may or may not include access to all course materials, and typically does not include access to assessments (or grades on the assessments, if they are accessible). MOOCs began as a free initiative and have quickly become monetized. However, the data did not show a corresponding increase in course information. For example, some courses did not list the cost for credentials, and none of the courses mentioned course size, something that participants may come to expect once they begin paying for a course experience. Also, the idea that more interactive course components are available for the paid option, and not with the free audit option, seems counter to the idea of democratization and accessibility, as interactivity would seemingly only be available to those who could afford it.

The process of coding and categorizing course descriptions was a slow and painstaking one, but it is one that we found to be useful and that will add to the overall literature that surrounds MOOCs. Such structural investigations of online courses are long overdue. Just as there is no monolithic online course, there is no monolithic MOOC. There are variations, and educators and researchers need to come to grips with these variations so that when we discuss them, we can use a common language. Understanding these variations is also important because the descriptions instructors and MOOC platforms provide to participants impact their course expectations. For example, cMOOC participants are often expected to have a much higher level of engagement with other participants. However, the data showed that several xMOOCs are highlighting interactive components in their course descriptions, which may come as a surprise to those who anecdotally refer to XMOOCs as non-interactive spaces.

There is also the matter of MOOC size. Unless instructors and providers have caps for MOOC size, it can be quite difficult to know what the size of a MOOC will be before, and even during, the offering of the course. However, it is possible for instructors and platform providers to design a course based on a target, maximum, or minimum course size. Providing that information in the overview or description of the MOOC can give participants a better idea of the type of experience to expect. Furthermore, with the increased number of certificate options for MOOCs, participants may want to know more information about the type of experience they can expect to have, in addition to the information currently provided regarding access to course materials and assessments. These MOOC certificates are provided for a fee and serve as credentials, so participants as well as outlets that consider accepting the certificate, including employers, higher education institutions, etc., may come to expect more information about the MOOC experience. Providing more information about the type of MOOC experience also has the potential to set certain MOOCs apart from each other. For example, if an employee wants to use a MOOC for professional development, her employer may have a more favorable perspective on MOOCs with a better description of the experience the employee will likely have in the course.

Overall, the typology was useful, but it was modified based on what worked and what did work in theory but did not work in practice. For example, the affiliation section was redefined because some MOOCs were offered jointly (i.e., through a third-party company and a university or through a third-party company as a part of another company). Also, because many MOOCs did not include information about course size, or expected course size, we could not provide that information. To answer the research questions, we found quite a few similarities between the MOOCs overall, including between cMOOCs and xMOOCs, and we found that there are 
differences among the course types as well: Not all cMOOCs address connectivity in the same way, and not all xMOOCs are simply "talking heads."

\section{Conclusion and Scholarly Significance}

The categorizations we have developed are important for a number of reasons. For example, MOOC instructors and MOOC learners could benefit from a more detailed description of courses. If we had wanted to sign up for one or more of the MOOCs from the study, we would have had to rely on the information provided via the information used as data, which did not always include a discussion of the type of course atmosphere participants could expect because that information was not always available. The chart could also prove useful during the planning stages of MOOC creation. Instructors may have thought through some of these areas already, of course, but some of the elements may not be considered until the instructor is in the middle of providing the course (or in some instances, after the course is over). Laying out many of these details ahead of time could help the instructor think through resource needs. For example, will s/he need a teaching assistant to make some aspects of the course possible? Will there be additional technology/software needs?

Another important aspect of these categorizations harkens back to ideas about "democratized" educational opportunities. In order to understand the benefit of MOOCs in a number of areas for a number of audiences, it is integral to explicate the varied nature of these courses. For example, we found that several xMOOC descriptions noted interactive components, which are often associated with cMOOCs. MOOCs are not a singular entity, and the more those who seek to create and deliver MOOCs think through these variations and ways to adjust or enhance them, the more robust the conversation will be related to leveraging them for greater educational purposes.

By having a clearer delineation of terms related to these courses, those interested in offering and/or taking them can have more detailed conversations about what the courses are, and any benefits or challenges associated with them. Our work adds the growing body of work on online learning in higher education. It also adds to organizational studies and the new field of MOOCs.

\section{Acknowledgment}

Special thanks to Erin Wojtkun for her early work with organizing the MOOC list. 


\section{References}

Andersen, R., \& Ponti, M. (2014). Participatory pedagogy in an open educational course: Challenges and opportunities. Distance Education, 35(2), 234-249. Retrieved from: http:// www.tandfonline.com/doi/abs/10.1080/01587919.2014.917703.

Aparicio, M., Bacao, F. \& Oliveira (2016). An e-Learning theoretical framework. Educational Technology \& Society, 19(1), 292-307.

Major, C., \& Blackmon, S. J. (2016). Massive open online courses: Variations on a new instructional form. In S. J. Blackmon \& C. Major (eds.), MOOCs and higher education: Implications for institutional research. New Directions for Institutional Research. San Francisco, California: Jossey-Bass.

Bruff, D. O., Fisher, D. H., McEwen, K. E., \& Smith, B. E. (2013). Wrapping in a MOOC: Student perceptions in blended learning. Journal of Online Learning and Teaching, 9(2), 187-199. Retrieved from: http://jolt.merlot.org/vol9no2/bruff 0613.htm.

Carver, L., \& Harrison, L. (2013). MOOCs and democratic education. Liberal Education, 99(4). Retrieved from https://aacu.org/liberaleducation/2013/fall/carver-harrison

Castaño, C., Maiz, I., \& Garay, U. (2015a). Design, motivation and performance in a cooperative MOOC course. Comunicar. Revista Cientí ca de Educación y Comunicación, 44, 19-26. Retrieved from: http://www.revistacomunicar.com/verpdf.php?numero=44\&articulo=442015- 02\&idioma $=$ en.

Castaño, C., Maiz, I., \& Garay, U. (2015b). Students perceptions of a university MOOC. RIED, 18(2), 197-224. Retrieved from: http://revistas.uned.es/index.php/ried/article/view/13444/13058.

Cheng, J. C. Y. (2014). An exploratory study of emotional affordance of a massive open online course. European Journal of Open, Distance and e-Learning, 17(1), 43-55. Retrieved from: http://www.eurodl.org/?p=archives\&year=2014\&halfyear=1\&article=607.

Clark, D. (2013, April 16). MOOCs: Taxonomy of 8 types of MOOC [Web log message]. Retrieved from http://donaldclarkplanb.blogspot.com/2013/04/moocs-taxonomy-of-8types-of-mooc.html

Collier, D., LaPorte, J., Seawright, J. (2012). Putting typologies to work: Concept formation, measurement, and analytic rigor. Political Research Quarterly, 65(1), 217-232. Retrieved from http://polisci.berkeley.edu/sites/default/files/people/u3827/PuttingTypologiesAppendixan dArticle 0.pdf

Conole, G. (2013, June 4). Week 5: A new classification of MOOCs [Web log message]. Retrieved from http://mooc.efquel.org/a-new-classification-for-moocs-grainne-conole/

Coursera (2017). Creative writing: The craft of character. Retrieved from https://www.coursera.org/learn/craft-of-character 
Dabbagh, N. (2005). Pedagogical models for e-learning: A theory-based design framework. International Journal of Technology in Teaching and Learning, 1(1). 25-44.

Delgado Kloos, C., Muñoz-Merino, P. J., Alario-Hoyos, C., Estevez Ayres, I., \& Fernández Panadero, C. (2015, March). Mixing and blending MOOC technologies with face-to-face pedagogies. In Global Engineering Education Conference (EDUCON), 2015 IEEE. Retrieved from: http://ieeexplore.ieee.org/xpls/icp.jsp?arnumber=7096090\&tag=1.

Digital Pedagogy Lab. (2015). MOOC MOOC : Critical pedagogy. Retrieved from http://www.digitalpedagogylab.com/hybridped/mooc-mooc-critical-pedagogy/

DS106 (2017). DS106. Retrieved from http://ds106.us/about/

Dillenbourg, P., Fox, A., Kirchner, C., Mitchell, J., \& Wirsing, M. (2014). Massive open online courses: Current state and perspectives. Dagstuhl Manifestos, 4(1), 1-27. Retrieved from: http://drops.dagstuhl.de/opus/volltexte/2014/4786/pdf/dagman-v004-i001-p00114112.pdf.

edX. (2017). Computation structures 3: Computer organization. Retrieved from https://www.edx.org/course/computation-structures-3-computer-mitx-6-004-3x-0

Fidalgo, A., Sein-Echaluce, M. L., \& García-Peñalvo, F. J. (2013). MOOC cooperativo. Una integración entre cMOOC у xMOOC. In A. Fidalgo \& M. L. Sein-Echaluce (Eds.), Actas del II Congreso Internacional sobre Aprendizaje, Innovación y Competitividad, CINAIC. (481-486) Madrid: Fundación General de la Universidad Politécnica de Madrid. Retrieved from: http://gredos.usal.es/jspui/bitstream/10366/122486/1/DIA PaperMOOCs.pdf.

Firmin, R., Schiorring, E., Whitmer, J. \& Willett, T. (2014). Case study: Using MOOCs for conventional college coursework. Distance Education, 35(2), 178-201. Retrieved from: http:// www.tandfonline.com/doi/abs/10.1080/01587919.2014.917707.

FutureLearn (2017). Physical theatre: Exploring the slap. Retrieved from https://www.futurelearn.com/courses/physical-theatre-exploring-the-slap

Gallego, M.J., Gámiz, S., \& Gutiérrez, E. (2015). Tendencias en la evaluación del aprendizaje en cursos en línea masivos y abiertos. Educación XXI, 18(2), 77-96. Retrieved from http://revistas.uned.es/index.php/educacionXX1/article/viewFile/14596/12996.

Guo, P. J., Kim, J. and Rubin, R. (2014, March). How video production affects student engagement: An empirical study of MOOC videos. ACM Conference on Learning at Scale. Retrieved from http://www.pgbovine.net/publications/edX-MOOC- videoproduction-and-engagement LAS-2014.pdf.

Israel, M.J. (2015). Effectiveness of integrating MOOCs in traditional classrooms for undergraduate students. The International Review of Research in Open and Distance Learning, 16(5), 102-118. Retrieved from: http://www.irrodl.org/index.php/irrodl/article/view/2222/3437.

Krasner, S. (1977). United States commercial and monetary policy: Unraveling the paradox of external strength and internal weakness. International Organization, 31, 635-671. 
Mason, R., \& Rennie, F. (2006) E-Learning: The key concepts. Abingdon Great Britain: Routledge.

Milligan, C., Littlejohn, A. \& Margaryan, A. (2013). Patterns of engagement in connectivist MOOCs. Journal of Online Learning and Teaching, 9(2), 149-159. Retrieved from: http:// jolt.merlot.org/vo19no2/milligan 0613.pdf.

Moessinger, S. (2013, September 13). MOOC around the world, part 6- "MOOCish" online ed resources. MOOC News \& Reviews. Retrieved from http://moocnewsandreviews.com/mooc-around-the-world-part-6-moocish-online-edresources/

Monedero, J. J., Cebrián, D., \& Desenne, P. (2015). Usability and satisfaction in multimedia annotation tools for MOOCs. Comunicar. Revista Cientí ca de Educación y Comunicación, 44, 55-62. Retrieved from:

http://www.revistacomunicar.com/verpdf.php?numero=44\&articulo=44- 2015$\underline{06 \& \text { idioma }=\text { en. }}$

MOOC.House. (2017). Introduction to business decision modeling with DMN. Retrieved from https://mooc.house/courses/signavio-dmn-intro

MOOC List. (2017). Retrieved from https://www.mooc-list.com

openSAP (2017). Developing software using design thinking. Retrieved from https://open.sap.com/courses/dt1

Politecnico Milano. (2017). To flip or not to flip: Discover the flipped classroom methodology Retrieved from https://www.pok.polimi.it/courses/course$\underline{\text { v1:Polimi }+F C 101+2016 \mathrm{M} 1 / \text { about }}$

Sangrá, A., González-Sanmamed, M., \& Anderson, T. (2015). Metaanálisis de la investigación sobre MOOC en el período 2013-2014. Educación XXI, 18(2), 21-59. Retrieved from: http:// revistas.uned.es/index.php/educacionXX1/article/view/14594.

SchoolEducation Gateway. (2017). Cultural diversity in your classroom. Retrieved from https://www.pok.polimi.it/courses/course-v1:Polimi+FC101+2016 M1/about

Schreier, M. (2014). Qualitative content analysis. The SAGE handbook of qualitative data analysis, 170-183.

Shah, D. (2017). https://www.class-central.com/report/mooc-course-report-may-2017/

Siemens, G. (2014). Connectivism: A learning theory for the digital age. Retrieved from http://er.dut.ac.za/bitstream/handle/123456789/69/Siemens_2005_Connectivism_A learn ing theory for the digital age.pdf? sequence $=1$

Siemens, G. (2012). MOOCs are really a platform. Elearnspace. Retrieved from http://www.elearnspace.org/blog/2012/07/25/moocs-are-really-a-platform/

Vargas, J. (2014). What can online course designers learn from research on machine-delivered instruction? Academe, 100(3). Retrieved from https://www.aaup.org/article/what-canonline-course-designers-learn-research-machine-delivered-instruction\#.WXzU0TOZMcg 
Veletsianos, G. (2013). Learner experiences with MOOCs and open online learning. Hybrid Pedagogy. Retrieved from: http://hybridpedagogy.github.io/LearnerExperiencesInMOOCs/.

Weber, Max (1978/1922). Economy and Society. Guenther Roth \& Claus Wittich (Eds.). Berkeley: University of California Press.

Wexler, E. (2015, October 19). MOOCs are still rising, at least in numbers. Retrieved from http://www.chronicle.com/blogs/wiredcampus/moocs-are-still-rising-at-least-innumbers $/ 57527$ 


\section{Appendix A}

The course descriptions below are verbatim from course websites:

MOOC MOOC: Critical Pedagogy

MOOC MOOC: Critical Pedagogy is a six-week exploration of Critical Pedagogy. As with previous iterations of MOOC MOOC, we are aiming less at amassing registrants and more at building community. Starting the week of January 19, 2015, we'll engage directly with both the foundational texts of Critical Pedagogy, and with modern thinkers whose work-by design or by coincidence - aligns with that approach. (Digital Pedagogy Lab, 2015)

\section{DS106: Digital StoryTelling (ds106)}

Digital Storytelling (also affectionately known as ds106) is an open, online course that happens at various times throughout the year the University of Mary Washington...but you can join in whenever you like and leave whenever you need. This course is free to anyone who wants to take it, and the only requirements are a real computer, a hardy internet connection, preferably a domain of your own and some commodity web hosting, and all the creativity you can muster. (DS106, 2017)

\section{Masterpieces of World Literature}

This literature course explores how great writers refract their world and how their works are transformed when they intervene in our global cultural landscape today. No national literature has ever grown up in isolation from the cultures around it; from the earliest periods, great works of literature have probed tensions, conflicts, and connections among neighboring cultures and often more distant regions as well. (MOOC List, 2017)

\section{Physical Theatre: Exploring the Slap}

This course introduces you to world-renowned Russian director Meyerhold's technique of biomechanics. It invites you to study and experience first-hand his revolutionary biomedical étude, 'The Slap'. Through a mixture of video, animation, discussion forums and practical exercises you will begin to understand Meyerhold's Russian actor training technique - a two-minute repeatable exercise used to develop balance, awareness, and expression. You will be invited to explore your own response to this unique approach to training and will share these responses with your fellow leaners. (FutureLearn, 2017)

\section{Creative Writing: The Craft of Character}

We will study the choices a writer makes to bring all characters to life on the page, and we will perform written exercises in order to develop a variety of writing and pre-writing techniques, in order to create a variety of characters. We will learn how to use our own life experiences, and the people we know (and how not to!). We will develop inner (thoughts and feelings) and out (appearance, habits, behavior) lives for our characters and see how that can lead us to richer and more interesting stories... (Coursera, 2017)

\section{Theatre and Globalization}

Learn how theatre and globalization have affected each other over the past century, and how to conduct your own research on global theatre histories. There are no prerequisites for this course. That said, an interest in common media depictions of globalization will help you understand the 
main arguments more quickly. Relatedly, reading and writing comfortably in English at the undergraduate level will enable your more active engagement in course discussion forums and peer assessment exercises. A basic understanding of theatre history, especially in the 20th century, would be advantageous. (Coursera, 2017)

\section{M101JS: MongoDB for Node.js Developers}

Learn everything you need to know to get started building a MongoDB-based app. This course will go over basic installation, JSON, schema design, querying, insertion of data, indexing and working with the Node.js driver. In the course, you will build a blogging platform, backed by MongoDB. (MOOC List, 2017)

\section{Developing Software Using Design Thinking}

...In this course, you will experience design thinking. To start down the path toward innovative solutions, focus on the problem first: Develop empathy for your users by 'putting yourself in their shoes,' and further understand their perspectives by defining a point-of-view statement. From there, you will start generating ideas and then move on to building low-resolution prototypes, which you can take back to your users for feedback. This will prepare you for the deliver phase, where you will learn how design thinking is connected to lean principles and single-piece processing. (OpenSAP, 2017)

\section{A Developer's Guide to Exploring and Visualizing IoT Data}

With a focus on the topic of Exploratory Data Analysis, the course provides an in-depth look at mathematical foundations of basic statistical measures, and how they can be used in conjunction with advanced charting libraries to make use of the world's best pattern recognition system - the human brain. Learn how to work with the data, and depict it in ways that support visual inspections, and derive to inferences about the data. Identify interesting characteristics, patters, trends, deviations or inconsistencies, and potential outliers. The goal is that you are able to implement end-to-end analytic workflows at scale, from data acquisition to actionable insights. (Coursera, 2017)

\section{Computation Structures 3: Computer Organization}

This computer science course is a bottom-up exploration of the abstractions, principles, and techniques used in the design of digital and computer systems. If you have a rudimentary knowledge of electricity and some exposure to programming, roll up your sleeves, join in and design a computer system! This is Part 3 of a 3-part series on digital systems, providing an introduction to the hardware/software interface and is based on a course offered by the MIT Department of Electrical Engineering and Computer Science. (edX, 2017)

\section{Accounting and Finance for IT Professionals}

This course presents an introduction to the basics of financial accounting and finance for IT professionals. The first part of the course will focus on understanding the most important financial statements, namely, the balance sheet, the income statement, and the statement of cash flows...The second part of the course will focus on the basics of finance... The course will also introduce the idea of real options, how they affect a project's NPV, and their impact of the decision to accept/reject a project... (Coursera, 2017) 
Agriculture, Economics and Nature

...This course will help you to contribute better decision making by farmers, or by agencies servicing agriculture, and it will help you to understand why farmers respond to policies and economic opportunities in the ways they do. You can use this course to improve your skills and knowledge, and to assess whether this is a subject that you'd like to study further. The course includes high-quality video lectures, interviews with experts, demonstrations of how to build economic models in spreadsheets, practice quizzes, and a range of recommended readings and options readings. Assessment is by a final exam. (Coursera, 2017)

\section{Economic Growth and Distributive Justice Part II-Maximize Social Wellbeing}

If you really care about the big questions in the economies and societies of the 21 st century, such as distributive justice - namely, inequality of income or wealth, and its correlation with economic growth - this course is meant for you. The knowledge you will gain can truly change your outlook on our world. (Coursera, 2017)

Statistical Shape Modelling: Computing the Human Anatomy

In this free online course, you will get insights form mathematics, statistics and machine learning, in order to address practical problems, as well as a theoretical and practical introduction to the open source software Scalismo (FutureLearn, 2017).

\section{China's Perspective on Climate Change}

This course will provide China's perspectives, policies, actions and effects on global climate changes to the international community. You will learn about the challenges and opportunities we are faced with on global climate in the world and in China, and will familiarize yourself with main policies, technical routines and international regulations. The knowledge presented in the course will benefit your understanding of significant theories and practical problems such as the energy revolution, economic development transition, low carbon economy development and the ecological civilization construction. (MOOC List, 2017)

The Genomics Era: The Future of Genetics in Medicine

This free online course will provide healthcare professionals with a basic grounding in genomic medicine. It will introduce you to new genomic technologies, which are revolutionising medicine and will, in time, provide the mainstay of patient diagnosis, treatment and disease prevention. (FutureLearn, 2017)

\section{Bioelectricity: A Quantitative Approach}

"Nerves, the heart, and the brain are electrical. How do these things work? This course presents fundamental principles, described quantitatively" (Coursera, 2017).

\section{Climate Change Mitigation in Developing Countries}

This course challenges you to consider how one might lift societies out of poverty while also mitigating greenhouse gas emissions. We explore the inherent complexity of developing country governments wanting to grow their economies in a climate friendly way. You will be introduced to an approach with which to address this challenge. The approach consists of a facilitated process whereby academic researchers and high-level influential actors within society co-produce 
knowledge. You will track this process in four Latin American countries-Brazil, Chile, Colombia, Peru, and South Africa. You will hear from various professionals about their contexts and the different challenges and opportunities the process includes. (Coursera, 2017)

\section{Applying to U.S. Universities}

This course will help international students (non-U.S. citizens) and non-native English speakers navigate the U.S. university admission process by offering practical information about the documents and pieces that make up a U.S. university application. More importantly, admission officers will discuss how they use those pieces to decide who is accepted and who is denied, so that you can understand the process beyond the pieces...Please note, while the English Language Programs are part of the University of Pennsylvania, this is not a course about applying to Penn. (Coursera, 2017)

\section{Teaching Mathematics with Technology}

Technology is an essential component of today's workplace and is a ubiquitous component of our society. Technology can be a useful tool to support students' engagement in and learning of mathematics. This course allows you to learn, along with colleagues from other schools and around the world, instructional practices that utilize technology to support students' mathematical learning. (MOOC List, 2017)

\section{Art \& Activity: Interactive Strategies for Engaging with Art}

Art can be a powerful catalyst for building skills and understanding a range of subjects. Intended for primary and secondary teachers of all disciplines, Art \& Activity builds upon the inquiry-based approaches of Art and Inquiry: Museum Teaching Strategies for Your Classroom, while delving into activity-based strategies that will make your students empowered participants. (Coursera, 2017)

To Flip or not to Flip_-Discover the Flipped Classroom Methodology

This MOOC is part of the MOOCs for Teachers series, which is devoted pedagogical innovation and is aimed at giving the change to teachers and people involved in instructional design to develop skills in the didactical area...In this MOOC you will have the chance to: learn the basics about flipped classroom; explore some shared experiences and identify key issues; start thinking about how to try it out in your course, using also the set of tools we will provide you with, and - why not - any useful open resource you find online. (Politecnico Milano, 2017)

\section{Disciplinary Literacy for Deeper Learning}

Disciplinary Literacy for Deeper Learning explores what it means to read, write, speak, and listen for learning and creating knowledge across disciplines, including science, mathematics, history/social studies, and English/language arts. In this six unit course, participants will learn how to engage students in deeper learning through disciplinary literacy practices and explore the model for inquiry-based disciplinary literacy. (MOOC List, 2017)

\section{Cultural Diversity in Your Classroom}

The course offers teachers an opportunity to access useful resources and exchange with peers on the challenging topic of cultural diversity in classrooms. The course is part of a 3-part series of courses exploring the topic of cultural diversity, the situation of newly arrived migrants in general 
and how to integrate newly arrived migrant students in schools and classrooms. (School Education Gateway, 2016)

Advanced Linear Models for Data Science 1: Linear Models

This class is an introduction to least squares from a linear algebraic and mathematical perspective. Before beginning the class make sure that you have the following: a basic understanding of linear algebra and multivariate calculus; a basic understanding of statistics and regression models; at least a little familiarity with proof based mathematics; basic knowledge of the $\mathrm{R}$ programing language. After taking this course, students will have a firm foundation in a linear algebraic treatment of regression modeling. (Coursera, 2017)

\section{Basic Data Descriptors, Statistical Distributions, and Application to Business Decisions}

This course is designed to introduce you to Business Statistics. We begin with the notion of descriptive statistics, which is summarizing data using a few numbers. Different categories of descriptive measures are introduced and discussed along with the Excel functions to calculate them. The notion of probability or uncertainty is introduced along with the concept of a sample and population data using relevant business examples... (Coursera, 2017)

\section{Rethinking International Tax Law}

In recent years, the international tax planning strategies of multinationals have become a source of - often heated - debate. This course provides learners with the tools to become fully informed participants in the debate by explaining the foundations and practice of international tax law as well as addressing current developments and the ethical aspects of tax planning. (Coursera, 2017)

\section{Business Fundamentals: Effective Networking}

Learn how to build and sustain your network to enhance your professional relationships and open up career opportunities (FutureLearn, 2017).

\section{Disability and a Good Life: Working with Disability}

Learn how disability intersects with human rights, and how a good life can be made possible for everyone (FutureLearn, 2016).

\section{Introduction to Business Decision Modeling with DMN}

In this course you will learn what DMN is, and how to read, use, understand, and model decision diagrams to guide your own organization to better business outcomes (Hasso Plattner Institute, 2017). 